\title{
Effect of breakfast consumption on the cognitive and academic performances in schoolchildren: A cross sectional study in Riyadh, Saudi Arabia
}

\author{
Maha Al Turki ${ }^{1,2 \star}$, Sarah Al Shloi ${ }^{1}$, Alhanouf Al Harbi ${ }^{1}$, Alanoud Al Agil ${ }^{1}$ and Fatmah Othman ${ }^{2,3}$ \\ ${ }^{1}$ Clinical Nutrition Program, King Saud bin Abdulaziz University for Health Sciences, Mail Code 3129, P.O Box 3660, \\ Riyadh 11481, Saudi Arabia. \\ ${ }^{2}$ King Abdullah International Medical Research Center, Riyadh, Saudi Arabia. \\ ${ }^{3}$ Research Unit, College of Applied Medical Sciences, King Saud bin Abdulaziz University for Health Sciences, Riyadh, \\ Saudi Arabia.
}

Accepted 9 July, 2019

\begin{abstract}
Breakfast is considered the most important meal of the day, especially for schoolchildren. To address the need for data to develop public health policies and programs for children in Saudi Arabia, we aimed to investigate the association between breakfast consumption habits and cognitive/academic performances among primary schoolchildren in Riyadh. A cross-sectional study was conducted among schoolchildren (aged 6 to 12 years), randomly selected from 8 primary schools. Anthropometric measurements were obtained to determine the body mass index (BMI)-for-age percentile. A self-reported questionnaire was used to collect information on their breakfast consumption habits. Cognitive functioning was assessed using the Raven Progressive Matrices test. The academic performance was determined using their scores in three subjects. Statistical analyses were performed using STATA 15 (Stata Corp., College Station, Texas). A total of 384 students were included in this study. The mean ( \pm SD) age of the subjects was $9.1 \pm 1.7$ years. Sixty percent of the schoolchildren reported consuming breakfast more than 4 times per week. Breakfast consumption was significantly associated with cognitive test scores. Children who consumed breakfast regularly were found to be twice more likely to achieve higher cognitive scores compared to those who were not regular breakfast consumers. A greater percentage of schoolchildren who consumed breakfast regularly achieved excellent scores in mathematics (78\%), science (87\%), and Arabic language (98\%). However, the difference in the academic performances of regular breakfast consumers and skippers did not achieve statistical significance. In conclusion, the findings of the present study support the hypothesis that regular consumption of breakfast has a short-term positive impact on the cognitive function and performance among young children. Nevertheless, the long-term beneficial effects of having regular breakfast on the academic performances of schoolchildren were not confirmed. School breakfast programs should, therefore, be developed and implemented to promote healthy eating habits among school-age children.
\end{abstract}

Keywords: Breakfast habits, academic performance, cognitive function, schoolchildren, Saudi Arabia.

*Corresponding author. E-mail: alturkimahaa@gmail.com.

\section{INTRODUCTION}

Breakfast has been labeled as the most important meal of the day, especially for school-aged children. This assumption is largely based on evidence which demonstrates the positive effects of consuming breakfast on children's body mass index (BMI), physical activities, school attendance and academic achievements (Koca et al., 2017; Dye and Lawton, 2009; De La Hunty et al., 2013; Sandercock et al., 2010). Despite inconsistent 
findings, studies have reported that consuming breakfast has a positive effect on the cognitive performance of schoolchildren, particularly in domains such as attention, memory, problem solving skills, and logical reasoning (Adolphus et al., 2016; lovino et al., 2016; Wesnes et al., 2003).

No definitive conclusions can be drawn from the existing data on the mechanisms that underlie the association between breakfast consumption and cognitive functions in children. One of the possible explanations is the nutritional effect of the breakfast meal on children's brain activity. Studies have considered the possibility that the nutritional benefits of consuming breakfast may play a role in the cognitive improvement observed among breakfast consumers. Data from several studies have demonstrated that breakfast consumers have a higher intake of fiber, vitamins (e.g., vitamin C, D, folic acid, and $\mathrm{B}_{12}$ ) and minerals (calcium and iron) (Pereira et al., 2018; Coulthard et al., 2017; Barr et al., 2014).

Studies have also shown that an increase in glucose levels following a meal may be involved in the short-term cognition improvement, which was observed in subjects who consumed breakfast (Feldman and Barshi, 2007). On the other hand, hypoglycemia has been reported to cause nervousness, tiredness, confusion, and slowed mental functions (Perlmuter et al., 2008). Studies have reported that brain glucose metabolism is higher in children compared to adults and that the metabolic rate of cerebral glucose utilization in children is approximately twice as high as in adults (Chugani, 1994; Chugani, 1998). The average cerebral blood flow and cerebral oxygen utilization are also greater among children compared to adults (Aaslid et al., 1984). Thus, children exert a higher demand on the glycogen stores, especially after the overnight fasting period, which is often longer during childhood than in adulthood. Breakfast consumption may, therefore, fulfill these high demands in this age group by providing them with adequate energy for the morning.

A good deal of earlier research has explored the importance of breakfast consumption on cognitive and academic performances in schoolchildren worldwide (Wesnes et al., 2003; Ral et al., 2012; Defeyter and Russo, 2013; Mahoney et al., 2005; Cooper et al., 2011; Liu et al., 2013; Mohd Nasir et al., 2012; Pivik et al., 2012; Baldinger et al., 2012). Considering the importance of consuming breakfast among school-aged students, and the need for data to develop public health policies and programs in Saudi Arabia, the current study aimed to investigate the association between self-reported breakfast habits and the cognitive/academic performances in elementary school students in Riyadh. It also aimed to explore the association between the breakfast composition, defined by food groups, and the academic performances of these children. Given the lack of such studies focusing on this age group in Saudi Arabia, this study is a significant one.

\section{MATERIALS AND METHODS}

\section{Study area and subjects}

A cross-sectional study was carried out in 8 primary schools (privet and public) in Riyadh, Saudi Arabia between September to November 2016. Schools at all levels in Saudi Arabia are gendersegregated. We selected female students between age of 6 and 12 years who attending those schools. The method of selecting the study participants, sample size estimation and data collection on nutrional status have been described in previously (Al Turki et al., 2018).

The study protocol was approved by the King Abdullah International Medical Research Centre (Ref. No. RYD-16-419812139269). Additionally, permission to carry out the study was obtained from the Saudi Ministry of Education, while verbal consent was obtained from the administrations of all the selected schools. Informed written consent was also obtained from the parents of the schoolchildren before the data collection.

\section{Data collection}

\section{Nutritional status}

The children's' ages were obtained from school records to determine the BMl-for-age percentile for our sample. For the anthropometric measurements, the weight and height were assessed by three trained researchers using an electronic body scale (Seca 769). These measurements were repeated twice for each participant, and the average value was considered. The children were asked to remove their shoes and any heavy pocket content before the measurements. The BMI-for-age percentile was first calculated as weight in kilograms divided by height in meters squared, which was then categorized as $<5$ th percentile, $\geq 5$ th and $<$ 85th percentile, $\geq 85$ th and $<$ 95th percentile, and $\geq 95$ th percentile. The nutritional status of the children was determined based on the WHO growth reference data (De Onis et al., 2007).

\section{Breakfast consumption habits}

Schoolchildren completed a self-report questionnaire consisting of 11 questions exploring their breakfast consumption habits, including the frequency and the types of items consumed (Khan, 2011). The content validity of this questionnaire has been checked and described in an earlier publication (Al Turki et al., 2018). Breakfast consumption frequency was calculated based on the number of breakfasts consumed per week. We categorize the participants into "breakfast consumer" if they consumed breakfast on a regular basis and into "Breakfast skippers" if they not based on their answer of related question on the questioner. Furthermore, we further redefined this based on frequency of breakfast consumption/ week. Thus we grouped the study population into students who consume breakfast to those who had breakfast more than 4 times per week and "and less than 4 days per week "group for students who consume 4 and more time to enhance the validity of our definition of breakfast consumption.

\section{Cognitive functioning}

Cognitive functioning was assessed using the Raven Progressive Matrices (RPM), a nonverbal test designed to assess cognitive ability in children aged between 5 to 11 years (Raven, 2008). This test helps measure the educative and reproductive abilities of children. It consists of 36 items in 3 sets of 12 items each that are listed in order of increasing difficulty. In each item, the child 
completes a pattern by identifying the missing element, which eliminates the influence of language and/or cultural bias. The RPM is a validated test and has been used previously to assess cognitive ability in children in several Arabian Countries, including Saudi Arabia (Abdel-Khalek et al., 2006; Abdel-Khalek, 2005; Batterjee et al., 2013).

The test was conducted during the first class of the school day. To ensure that the children are familiar with the test, the researchers spent a few minutes explaining the instructions and answering any questions the children had. The test was administrated individually in a quiet classroom and was completed in 60 minutes.

The results of the test were presented as the number of correct responses, and the final score was calculated by adding the scores for each of the three sets. The final scores were presented as a percentile scale as follows: superior intellectual ability: score $\geq 95$; above average: score $\geq 75$ and $<95$; average: score $>25$ and $<75$; below average: score $>5$ and $\leq 25$ and intellectually defective: score $\leq 5$.

\section{Academic performance}

The academic performances of the children were assessed based on the academic year's final exam scores, which were obtained from the school records. The final score represents the continuous assessment during the term and the final assessment for each subject. The final scores for Mathematics, Science, and the Arabic language were chosen to be included in the study. According to the Saudi Educational System for primary level, schoolchildren are graded as follows: excellent: $\geq 95$, advanced: between 85 and 95, average: between 75 and 85, and fail: < 75 (Saudi Ministry of Education, 2017).

\section{Statistical analysis}

Descriptive statistics were used to describe the characteristics of the participants. Mean and standard deviation (SD) have been used for continuous variables and frequencies and percentages for categorical variables. The Pearson chi-square test was used to examine the association between breakfast consumption habits and cognitive/academic performance (as categorical variables) if one or more of the cells had an expected frequency of five or more. Otherwise, Fisher's exact test was used. For analyzing the association between breakfast consumption habits and cognitive performance (as a continuous variable), we used the independent ttest. Logistic regression analyses were performed to determine the effects of breakfast consumption on cognitive test scores. For this analysis we regrouped the cognitive scores into "below average" that include the intellectually impaired and below average scores and "average and above" category that include the average, above average, and intellectually superior scores. The effect values were reported as odds ratio (OR) with their 95\% confidence intervals (Cls). A $p$ value of less than 0.05 was considered statistically significant. All statistical analyses were performed using STATA 15 (Stata Corp., College Station, Texas).

\section{RESULTS}

\section{Demographic characteristics of participants and their breakfast consumption habits}

A total of 384 schoolchildren aged between 6 and 12 years (mean $9.1 \pm 1.7$ years) were recruited for the study.
This sample represented all grade levels at the primary school system in Saudi Arabia (6 grades). While 61\% of the participants had normal BMI, $30 \%$ of them were overweight or obese, and $9 \%$ were underweight. Table 1 shows the demographic profiles of all the children in the study, including both breakfast consumers and skippers.

Eighty eight percent of the participants reported that they consumed breakfast on a regular basis. The breakfast skippers were found to be older (mean age: $9.7 \pm 1.3$ years) than the breakfast consumers (mean age: $9.1 \pm 1.7$ years). Of the children enrolled in public schools, $51 \%$ reported that they consumed breakfast regularly, compared to $48 \%$ from private schools. The BMl was comparable between the two groups.

After restricting the definition of "breakfast consumer" to those who had breakfast more than 4 times per week, the percentage of breakfast consumers dropped to $60 \%$. While more than half of the schoolchildren in our sample consumed breakfast more than 4 times per week (58\%), only $2 \%$ did so 5 or more times per week.

\section{Association between breakfast consumption habits and cognitive/academic performances}

The mean raw cognitive score of the schoolchildren in our sample was $23.7 \pm 7.5$. Breakfast consumers had a higher mean row cognitive score $(23 \pm 7.6)$ compared to the breakfast skippers $(22 \pm 5.9)$. Based on the cognitive test scores, while $14 \%$ of the schoolchildren were intellectually superior, $31 \%$ were above average, 39\% were average, and $15 \%$ were either below average or intellectually impaired (Table 2). Using Fisher's exact test, we found a statistically significant relationship between the cognitive test scores categories and breakfast consumption habits $(p=0.002)$. While, a greater percentage of breakfast consumers had excellent scores in Math (78\%), Science (87\%), and Arabic (98\%), the performance was not significantly different from that reported for the breakfast skippers.

We divided the study population into two categories based on the reported frequency of breakfast intake per week: those consuming breakfast (a) more than 4 times a week (consumers), and (b) less than 4 times a week (skippers). Our findings showed that the former group achieved higher cognitive scores compared to the latter group (Table 2). Out of the 176 schoolchildren who were "above average" and "intellectually superior," $61 \%$ reported that they consumed breakfast more than 4 times per week. Moreover, a greater percentage of breakfast consumers also achieved higher academic scores in Math, Science, and Arabic language. However, the difference in the academic performances between the two groups, in general, did not reach a significant level.

After recategorizing the cognitive scores as (a) below average (intellectually impaired and below average as one category) and (b) average and above (average, 
Table 1. Demographic characteristics of the schoolchildren.

\begin{tabular}{|c|c|c|c|}
\hline \multirow{3}{*}{ Characteristics } & \multicolumn{3}{|c|}{ Breakfast consumption habits } \\
\hline & $\begin{array}{c}\text { All } \\
n=384\end{array}$ & $\begin{array}{c}\text { Breakfast skippers } \\
\qquad n=45\end{array}$ & $\begin{array}{c}\text { Breakfast consumers } \\
\qquad n=339\end{array}$ \\
\hline & Mean \pm SD & Mean \pm SD & Mean \pm SD \\
\hline Age (years) & $9.15 \pm 1.7$ & $9.7 \pm 1.3$ & $9.1 \pm 1.7$ \\
\hline Weight (KG) & $32 \pm 11.1$ & $35 \pm 10.4$ & $31 \pm 11.1$ \\
\hline Height (cm) & $132.7 \pm 11.7$ & $136 \pm 8.5$ & $132 \pm 11.9$ \\
\hline \multirow[t]{2}{*}{ BMI Percentile } & $54.6 \pm 33.7$ & $60.5 \pm 31.2$ & $53.8 \pm 34.1$ \\
\hline & $n(\%)$ & $n(\%)$ & $n(\%)$ \\
\hline \multicolumn{4}{|l|}{ School type } \\
\hline Public & $192(50)$ & $17(37)$ & $175(51)$ \\
\hline Private & $192(50)$ & $28(62)$ & $164(48)$ \\
\hline \multicolumn{4}{|c|}{ BMI percentile classification $\left(\mathrm{kg} / \mathrm{m}^{2}\right)^{\mathrm{a}}$} \\
\hline Underweight & $33(8)$ & $2(4)$ & $31(9)$ \\
\hline Normal & $237(61)$ & $29(64)$ & $208(61)$ \\
\hline Overweight & $51(13)$ & $7(15)$ & $44(13)$ \\
\hline Obese & $63(16)$ & $7(15)$ & $56(16)$ \\
\hline \multicolumn{4}{|c|}{ School grade distribution } \\
\hline Grade 1 & $66(17)$ & $1(2)$ & $65(19)$ \\
\hline Grade 2 & $64(16)$ & $4(9)$ & $60(17)$ \\
\hline Grade 3 & $68(17)$ & $17(37)$ & $51(15)$ \\
\hline Grade 4 & $58(15)$ & $4(8)$ & $54(15)$ \\
\hline Grade 5 & $58(15)$ & $9(20)$ & $49(14)$ \\
\hline Grade 6 & $70(18)$ & $10(22)$ & $60(17)$ \\
\hline
\end{tabular}

SD Standard Deviation

a. $\leq 5 \%$ is underweight, $5-84 \%$ is normal, $85-95 \%$ is overweight, $\geq 95 \%$ is obese.

above the average, and intellectually superior as one category), it was found that most of the schoolchildren who reported skipping breakfast achieved below average scores while more than half of our total sample (56\%) who were breakfast consumers had average and above cognitive scores. The unadjusted odds ratio was 2.3 (95\% Cl: 1.2-4.5) indicating that children who consumed breakfast regularly were twice more likely to achieve higher cognitive scores compared to those who were breakfast skippers (Table 3).

\section{Association between breakfast composition and cognitive/academic performance}

Table 4 summarizes the cognitive and academic performances of the schoolchildren based on the breakfast composition they reported. A higher percentage of students who demonstrated excellent performances in Math, Science, and Arabic language consumed more milk, dairy products, and carbohydrates for breakfast compared to the students with poorer performance in the same subjects. The types of food groups consumed for breakfast did not show a statistically significant association with the cognitive/ academic performances, except for the association between the consumption of carbohydrates and performance in Arabic language $(p<$ 0.05).

\section{DISCUSSION}

Several studies have investigated the positive effects of breakfast consumption on cognitive and academic performances in children and adolescents (Adolphus et al., 2016; Wesnes et al., 2003; Ral et al., 2012; Defeyter and Russo, 2013; Mahoney et al., 2005; Cooper et al., 2011; Liu et al., 2013; Mohd Nasir et al., 2012; Pivik et al., 2012; Baldinger et al., 2012). This study, to the best of our knowledge, is the first one to explore the same among schoolchildren in Saudi Arabia. This crosssectional study confirmed the hypothesis that breakfast consumption is positively related to the cognitive performance of schoolchildren, including attention, 
Table 2. Distribution of cognitive and academic performances according to breakfast consumption habits.

\begin{tabular}{|c|c|c|c|c|c|c|c|}
\hline \multirow[b]{2}{*}{ Variables } & \multirow{2}{*}{$\begin{array}{c}\text { All } \\
n(\%)\end{array}$} & \multicolumn{3}{|c|}{ Breakfast consumption habits $^{\text {a }}$} & \multicolumn{3}{|c|}{ Frequency of breakfast consumption/ week } \\
\hline & & $\begin{array}{c}\text { Breakfast skippers } \\
\qquad n=45\end{array}$ & $\begin{array}{c}\text { Breakfast consumers } \\
\qquad n=339 \\
\end{array}$ & $p$ value* & $\begin{array}{c}<4 \text { days/week } \\
n=151\end{array}$ & $\begin{array}{c}\geq 4 \text { days/week } \\
n=233\end{array}$ & $p$ value $^{*}$ \\
\hline \multicolumn{8}{|c|}{ Cognitive performance } \\
\hline Intellectually impaired & $35(9)$ & $2(6)$ & $33(94)$ & \multirow{5}{*}{$<0.05$} & $15(43)$ & $20(57)$ & \multirow{5}{*}{0.27} \\
\hline Below average & $22(6)$ & 0 & $22(100)$ & & $5(22)$ & $17(77)$ & \\
\hline Intellectually average & $151(39)$ & $14(9)$ & $137(90)$ & & $63(41.7)$ & $88(58)$ & \\
\hline Above the average & $121(31)$ & $26(21)$ & $95(78)$ & & $51(42)$ & $70(57.8)$ & \\
\hline Intellectually superior & $55(14)$ & $3(5.4)$ & $52(94)$ & & $17(31)$ & $38(69)$ & \\
\hline \multicolumn{8}{|c|}{ Academic performance ${ }^{b}$} \\
\hline \multicolumn{8}{|c|}{ Math } \\
\hline Excellent & $331(86)$ & $41(13)$ & $289(87)$ & \multirow{4}{*}{0.67} & $133(40)$ & $198(59)$ & \multirow{4}{*}{0.51} \\
\hline Good & $46(12)$ & $3(6)$ & $43(93)$ & & $16(34.7)$ & $30(56)$ & \\
\hline Average & $4(1)$ & 0 & $4(100)$ & & $2(50)$ & $2(50)$ & \\
\hline Fail & $3(0.7)$ & 0 & $3(100)$ & & 0 & $3(100)$ & \\
\hline \multicolumn{8}{|l|}{ Science } \\
\hline Excellent & $351(91)$ & $43(12)$ & $308(87)$ & \multirow{4}{*}{0.61} & $140(40)$ & $211(60)$ & \multirow{4}{*}{0.74} \\
\hline Good & $23(6)$ & $1(4.3)$ & $22(95)$ & & $9(39)$ & $14(61)$ & \\
\hline Average & $6(1.5)$ & $1(16.6)$ & $5(83)$ & & $1(16)$ & $5(83)$ & \\
\hline Fail & $4(1)$ & 0 & $4(100)$ & & $1(25)$ & $3(75)$ & \\
\hline \multicolumn{8}{|l|}{ Arabic language } \\
\hline Excellent & $318(82)$ & $34(10.6)$ & $284(89)$ & \multirow{4}{*}{0.26} & $123(38)$ & $195(61)$ & \multirow{4}{*}{0.10} \\
\hline Good & $54(14)$ & $10(18.5)$ & $44(81)$ & & $26(48)$ & $28(51)$ & \\
\hline Average & $6(1.5)$ & 0 & $6(100)$ & & 0 & $6(100)$ & \\
\hline Fail & $6(1.5)$ & $1(16.6)$ & $5(83)$ & & $2(33)$ & $4(66.6)$ & \\
\hline
\end{tabular}

$n(\%)$ are presented

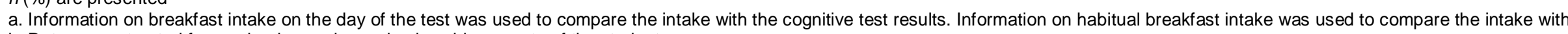
b. Data was extracted from school records academic achievements of the students.

${ }^{*} p$ value was calculated using a chi-square test if one or more of cells had an expected frequency of five or more. Otherwise, Fisher's exact test was used.

memory, and executive functions $(p<0.05)$. Our findings are consistent with those from several previous studies (Adolphus et al., 2016; Wesnes et al., 2003; Defeyter and Russo, 2013; Mahoney et al., 2005; Cooper et al., 2011; Liu et al., 2013; Mohd Nasir et al., 2012; Pivik et al., 2012;
Edwards et al., 2011; Edefonti et al., 2014). In their review, Galioto and Spitznagel (2016) have identified thirteen intervention studies that demonstrate the positive effect of breakfast on attention in both children and adults. In our study, schoolchildren who were regular breakfast consumers were found to be twice more likely to achieve higher cognitive scores compared to the breakfast skippers.

Compared to breakfast skippers, the consumers had higher academic scores in Mathematics, Science, and Arabic language, although the 
Table 3. Association between breakfast consumption habits/frequency and cognitive scores.

\begin{tabular}{|c|c|c|c|c|c|c|}
\hline \multirow[b]{2}{*}{$\begin{array}{l}\text { Cognitive } \\
\text { performance }\end{array}$} & \multicolumn{3}{|c|}{ Breakfast consumption habits } & \multicolumn{3}{|c|}{ Frequency of breakfast consumption/week } \\
\hline & $\begin{array}{c}\text { Breakfast } \\
\text { skippers } \\
n(\%)\end{array}$ & $\begin{array}{c}\text { Breakfast } \\
\text { consumer } \\
n(\%)\end{array}$ & OR $95 \% \mathrm{Cl}$ & $\begin{array}{c}<4 \text { days/week } \\
n(\%)\end{array}$ & $\begin{array}{c}\geq 4 \text { days week } \\
n(\%)\end{array}$ & OR $95 \% \mathrm{Cl}$ \\
\hline Below average $^{a}$ & $29(64)$ & $147(43)$ & 1 & $68(45)$ & $108(46)$ & 1 \\
\hline Average and above ${ }^{b}$ & $16(35)$ & $192(56)$ & $.36(1.2-4.5)$ & $83(54)$ & $125(53)$ & $0.94(0.6-1.43)$ \\
\hline
\end{tabular}

OR, Odds Ratio. $\mathrm{Cl}$, confidence interval.

a. The below average category includes the intellectually impaired and below average scores.

b. The average and above category includes the average, above average, and intellectually superior scores.

differences were not significant. Studies on the impact of breakfast consumption on academic performances have produced mixed results (Vishnukumar et al., 2018; Taha, 2017; Adolphus et al., 2013; Littlecott et al., 2016). The use of the end-of-year academic grades to measure the effects of breakfast consumption may be not ideal, since the grades could be affected by several confounding factors such as the quality of school (teaching quality, facilities, and class size), family (parent's education levels and socioeconomic status) and the individual characteristics of the students (behavior, motivation and personality) (Mushtaq and Khan et al., 2012).

Overall, our findings are in line with the suggestion that the beneficial effects of regular breakfast consumption on intellectual and cognitive performances are modest and short-term (4 hours post consumption) (Galioto and Spitznagel, 2016). In our study, the schoolchildren took the cognitive test early in the morning (between 7:00 and 8:00 a.m.), which could explain the significant effects of breakfast consumption on their scores. An additional implication of this finding is the possibility that, demanding mental tasks are more sensitive to nutritional influences, (Russo, 2013; Cooper et al., 2011; Scholey et al., 2001) which is consistent with several studies that have suggested that the time of testing after consumption of breakfast should be taken into consideration. The strongest effects of breakfast consumption on test performances have been reported at 130- and 200minutes post ingestion (Wesnes et al, 2003; Ingwersen et al., 2007).

The present study also examined the effect of the selfreported breakfast composition on both cognitive and academic performances. Consistent with the literature, we found that the composition of breakfast, in general, did not influence the academic or cognitive performances except for an association between carbohydrates and better performance in the Arabic language (Edefonti et al., 2014; Galioto and Spitznagel, 2016). We found that a greater percentage of students who consumed milk, dairy products, and carbohydrates for daily breakfast achieved excellent scores in Math, Science, and Arabic languages. However, the difference in their performances when compared to those who did not consume these food types for breakfast did not reach a significant level.
Edefonti et al. (2014) reviewed 16 studies that compared cognition in healthy adults after breakfast containing different macronutrient compositions and found no significant differences. Nevertheless, a limited number of studies have reported that breakfast composition influences cognitive functions (Michaud et al., 1991; Benton et al., 2003; Holt et al., 1999). These inconsistent results could be due to the different methods used for assessing or categorizing the breakfast intake. The use of the glycemic index (GI) as a measure to assess the breakfast composition, as suggested by Micha et al. (2011) supports a previous hypothesis that the glucose status has a direct effect on cognitive function.

The findings of our study emphasize the importance of developing and implementing school nutrition policies to support healthy eating behaviors in schoolchildren during their formative years, and to apply the recommended nutritional standards to the items sold at the school canteens. Given the positive experiences reported in other countries, it would also be a good idea to restart the school-based breakfast program (discontinued in 1981), which provided free breakfast to all students across the country, or to at least run the program with a suitable budget for the students (Christensen et al. 2019).

\section{Strength and limitation}

This study has some limitations that deserve attention. First, we did not distinguish between week-day and weekend-breakfast consumption frequencies. Second, since this is designed as a cross-sectional study, any explanation regarding the mechanism and direction of associations between breakfast intake and cognition or academic performance is not possible. The validity of the findings from such a study design may be affected by unmeasured confounding factors (Adolphus et al., 2017). Further longitudinal and experimental studies are recommended for an in-depth assessment of the association between breakfast intake and cognitive/academic performances among Saudi schoolchildren, using a detailed dietary assessment, and keeping in consideration the potential confounding factors. 
Table 4. Association between the reported breakfast composition and the cognitive/academic performances.

\begin{tabular}{|c|c|c|c|c|c|c|c|c|c|}
\hline \multirow{3}{*}{ Variables } & \multicolumn{9}{|c|}{ Food Groups $^{\text {a }}$} \\
\hline & \multicolumn{3}{|c|}{ Milk \& dairy products } & \multicolumn{3}{|c|}{ Protein group } & \multicolumn{3}{|c|}{ Carbohydrates group } \\
\hline & No & Yes & $p$ value ${ }^{*}$ & No & Yes & $p$ value ${ }^{\star *}$ & No & Yes & $p$ value $^{*}$ \\
\hline Cognitive performance & & & \multirow{6}{*}{0.71} & & & & & & 0.50 \\
\hline Intellectually impaired & $11(20)$ & $44(80)$ & & $35(63)$ & $20(36)$ & 0.86 & $10(18)$ & $45(81)$ & \\
\hline Below average & $22(18)$ & $99(81)$ & & $85(70)$ & $36(29)$ & & $32(26)$ & $89(73)$ & \\
\hline Intellectually average & $38(25)$ & $113(74)$ & & $100(66)$ & $51(33)$ & & $38(25)$ & $113(74)$ & \\
\hline Above the average & $5(22)$ & $17(77)$ & & $14(63)$ & $8(36)$ & & $3(13)$ & $19(86)$ & \\
\hline Intellectually superior & $7(20)$ & $28(80)$ & & $25(71)$ & $10(28)$ & & $6(17)$ & $29(82)$ & \\
\hline \multicolumn{10}{|l|}{ Academic performance ${ }^{b}$} \\
\hline \multicolumn{10}{|l|}{ Math } \\
\hline Excellent & $75(22)$ & $256(77)$ & \multirow{4}{*}{0.46} & $222(67)$ & $109(32)$ & 0.46 & $78(23)$ & $253(76)$ & 0.73 \\
\hline Good & $7(15)$ & $39(84)$ & & $30(65)$ & $16(34)$ & & $10(21)$ & $36(78)$ & \\
\hline Average & 0 & $4(100)$ & & $4(100)$ & 0 & & 0 & $4(100)$ & \\
\hline Fail & $1(33)$ & $2(66)$ & & $3(100)$ & 0 & & $1(33)$ & $2(66)$ & \\
\hline \multicolumn{10}{|l|}{ Science } \\
\hline Excellent & $75(21)$ & $276(78)$ & \multirow{4}{*}{0.59} & $235(66)$ & $116(33)$ & 0.43 & $85(24)$ & $266(75)$ & 0.57 \\
\hline Good & $7(30)$ & $16(69)$ & & $17(73)$ & $6(26)$ & & $3(13)$ & $20(86)$ & \\
\hline Average & $1(16)$ & $5(83)$ & & $3(50)$ & $3(50)$ & & $1(16)$ & $5(83)$ & \\
\hline Fail & 0 & $4(100)$ & & $4(100)$ & 0 & & 0 & $4(100)$ & \\
\hline \multicolumn{10}{|l|}{ Arabic language } \\
\hline Excellent & $72(22)$ & $246(77)$ & \multirow{4}{*}{0.70} & $213(66)$ & $105(33)$ & 0.65 & $67(21)$ & $251(78)$ & $<0.05$ \\
\hline Good & $10(18)$ & $44(81)$ & & $39(72)$ & $15(27)$ & & $20(37)$ & $34(62)$ & \\
\hline Average & 0 & $6(100)$ & & $3(50)$ & $3(50)$ & & 0 & $6(100)$ & \\
\hline Fail & $1(16)$ & $5(83)$ & & $4(66)$ & $2(33)$ & & $2(33)$ & $4(66)$ & \\
\hline
\end{tabular}

a. breakfast composition data was extracted from the self-reported questionnaire. $\mathrm{b}$. The academic performance of the schoolchildren was extracted from the school records;

* $p$ value was calculated using the chi-square test if the one or more of the cells had an expected frequency of five or more; otherwise, Fisher's exact test was used.

\section{CONCLUSIONS}

Our findings support the hypothesis that consumption of breakfast has a short-term positive impact on cognitive performance among school-aged children. Nevertheless, the long-term beneficial effects of breakfast, as indicated by academic performances, were not confirmed. Therefore, the development of school breakfast programs is recommended to promote healthy eating habits among school-age children.

\section{ACKNOWLEDGEMENTS}

We would like to express our sincere gratitude to 
the Saudi Ministry of Education for giving us the chance to conduct this study in several schools in Riyadh City. We are also thankful to the school administrations and teachers for their valuable support during the data collection process. We are also immensely grateful to all the students for devoting their valuable time to be a part of our study.

\section{REFERENCES}

Aaslid R, Huber $P$, Nornes $H$, 1984. Evaluation of cerebrovascular spasm with transcranial Doppler ultrasound. J Neurosurg, 60: 37-41.

Abdel-Khalek A, 2005. Reliability and factorial validity of the standard progressive matrices among Kuwaiti children ages 8 to 15 years. Perceptual Motor Skills, 101(2): 409-412.

Abdel-Khalek A, Ahmed M, Raven J, 2006. Normative data from the standardization of raven's standard progressive matrices in Kuwait in an international context. Soc Behav Personality: An Int J, 34: 169180.

Adolphus K, Bellissimo N, L Lawton, Ford N, Rains T, de Zepetnek J, Dye L, 2017. Methodological challenges in studies examining the effects of breakfast on cognitive performance and appetite in children and adolescents, Adv Nutr, 8(1): 184S-196S.

Adolphus K, Lawton C, Champ L, Dye L. 2016. The effects of breakfast and breakfast composition on cognition in children and adolescents: A systematic review. Adv Nutrit, 7(3): 590S-612S.

Adolphus K, Lawton C, Dye L, 2013. The effects of breakfast on behavior and academic performance in children and adolescents. Front Hum Neurosci, 7: 425.

Al Turki M, Al Shloi S, Al Harbi A, Al Agil A, Philip W and Qureshi S, 2018. Breakfast consumption habits among schoolchildren: A crosssectional study in Riyadh, Saudi Arabia. Int Res J Med Med Sci, 6(2): 50-55.

Baldinger N, Krebs A, Muller R, Aeberli I, 2012. Swiss children consuming breakfast regularly have better motor functional skills and are less overweight than breakfast skippers. J Am Coll Nutr, 31: 8793.

Barr SI, DiFrancesco L, Fulgoni VL, 2014. Breakfast consumption is positively associated with nutrient adequacy in Canadian children and adolescents. 3rd edition. Br J Nutr, 112(8): 1373-83.

Batterjee A, Khaleefa O, Ali K, Lynn R, 2013. An increase of intelligence in Saudi Arabia, 1977-2010. Intelligence, 41(2): 91-93.

Benton D, Ruffin M, Lassel T, Nabb S, Messaoudi M, Vinoy S, 2003. The delivery rate of dietary carbohydrates affects cognitive performance in both rats and humans. Psychopharmacology. 166(1): 86-90.

Christensen C, Mikkelsen B, Tof U, 2019. The effect of introducing a free breakfastclub on eating habits among students atvocational schools. BMC Public Health, 19: 369.

Chugani H, 1994. Development of regional brain glucose metabolism in relation to behavior and plasticity. In Human Behavior and the Developing Brain, 153-175 [G Dawson and KW Fischer, editors]. New York: Guildford Press.

Chugani H, 1998. A critical period of brain development: studies of cerebral glucose utilization with PET. Prev Med, 27: 184-188.

Cooper S, Bandelow S, Nevill M, 2011. Breakfast consumption and cognitive function in adolescent schoolchildren. Physiol Behav, 103: 431-439

Coulthard J, Palla L, Pot G, 2017. Breakfast consumption and nutrient intakes in 4-18-year-olds: UK National Diet and Nutrition Survey Rolling Programme (2008-2012). Br J Nutr, 118(4): 280-290.

De la Hunty A, Gibson S, Ashwell M, 2013. Does regular breakfast cereal consumption help children and adolescents stay slimmer? A systematic review and meta-analysis. Obes Facts, 6(1): 70-85.

De Onis M, Onyango A, Borghi E, Siyam A, Nishida C, Siekmann J, 2007. Development of a WHO growth reference for school-aged children and adolescents. Bulletin of the World Health Organization, 85:660-7. Retrieved from: https://www.who.int/growthref/growthref_ who_bull/en/.
Defeyter M, Russo R, 2013. The effect of breakfast cereal consumption on adolescents' cognitive performance and mood. Front Hum Neurosci, 7: 789.

Dye L, Lawton C, 2009. Systematic review of the effect of breakfast on the cognitive performance of children and adolescents. NNR, 22: 220-243.

Edefonti V, Rosato V, Parpinel M, Nebbia G, Fiorica L, Fossali E, Ferraroni M, Decarli A, Agostoni C, 2014. The effect of breakfast composition and energy contribution on cognitive and academic performance: a systematic review. Am J Clin Nutr, 100(2): 626-656.

Edwards J, Mauch L, and Winkelman M, 2011. Relationship of nutrition and physical activity behaviors and fitness measures to academic performance for sixth graders in a Midwest city school district. J School Health, 81: 65-73.

Feldman J, Barshi I, 2007. The Effects of Blood Glucose Levels on Cognitive Performance: A Review of Literature. Moffett Field California, NASA Ames Research Center, (NASA/TM-2007-214555).

Galioto R, Spitznagel M, 2016. The effects of breakfast and breakfast composition on cognition in adults. Adv Nutr, 7(3): 576S-589S.

Holt S, Delargy H, Lawton C, Blundell J, 1999. The effects of high carbohydrate vs high-fat breakfasts on feelings of fullness and alertness, and subsequent food intake. Int J Food Sci Nutr, 50(1): 13-28.

Ingwersen J, Defeyter M, Kennedy D, Wesnes K, Scholey A, 2007. A low glycaemic index breakfast cereal preferentially prevents children's cognitive performance from declining throughout the morning. Appetite, 49: 240-244.

lovino I, Stuff J, Liu Y, Brewton C, Dovi A, Kleinman R, Nicklas T, 2016. Breakfast consumption has no effect on neuropsychological functioning in children: a repeated-measures clinical trial. Am J Clin Nutr, 104(3): 715-721.

Khan A, 2011. The relationship between breakfast, academic performance and vigilance in school aged children. Published dissertation in partial fulfillment of the requirements for the degree of Master's, Murdoch University, Perth, WA

Koca T, Akcam M, Serdaroglu F, Dereci S, 2017. Breakfast habits, dairy product consumption, physical activity, and their associations with body mass index in children aged 6-18. Eur J Pediatr, 176(9): 1251-1257.

Littlecott HJ, Moore GF, Moore L, Lyons RA, Murphy S, 2016. Association between breakfast consumption and educational outcomes in 9-11-year-old children. Public Health Nutr, 19(9): 15751582.

Liu J, Hwang W, Dickerman B, Compher C, 2013. Regular breakfast consumption is associated with increased IQ in kindergarten children, Early Hum Dev, 89(4): 257-262.

Mahoney C, Taylor H, Kanarek R, Samuel P, 2005. Effect of breakfast composition on cognitive processes in elementary school children. Physiol Behav, 85: 635-645.

Micha R, Rogers P, Nelson M, 2011. Glycemic index and glycemic load of breakfast predict cognitive function and mood in school children: a randomized controlled trial. British Journal of Nutrition, 106: 15521561.

Michaud C, Musse N, Nicolas J, Mejean L, 1991. Effect of breakfast size on short term memory, concentration, mood, and blood glucose. J Adolesc Health, 12: 53-57.

Mohd Nasir M, Norimah A, Hazizi A, Nurliyana A, Loh S, Suraya I, 2012. Child feeding practices, food habits, anthropometric indicators and cognitive performance among preschoolers in Peninsular Malaysia. Appetite, 58: 525-530.

Mushtaq I, Khan S, 2012. Factors affecting students' academic performance. Glob J Manag Bus Res, 12(9): 1.

Pereira JL, Castro MA, Hopkins S, Gugger C, Fisberg RM, Fisberg M, 2018. Prevalence of consumption and nutritional content of breakfast meal among adolescents from the Brazilian National Dietary Survey. J Pediatr, 94(6): 630-641.

Perlmuter L, Brian P, Flanagan B, Parinda $H$, Shah $P$, Sant $P$, Singh S, 2008. Glycemic control and hypoglycemia. Diabetes Care, 31(10): 2072-2076

Pivik R, Tennal K, Chapman S, Gu Y, 2012. Eating breakfast enhances the efficiency of neural networks engaged during mental arithmetic in school-aged children. Physiol Behav, 106: 548-555. 
Ral T, Heo M, Whiteford L, Faith M, 2012. Effects on cognitive performance of eating compared with omitting breakfast in elementary schoolchildren. J Dev Behav Pediatr, 33: 9-16.

Raven J, 2008. Manual Coloured. Progressive Matrices and Crichton. Vocabulary Scale. NCS Pearson, Inc. UK.

Sandercock GR, Voss C, Dye L, 2010. Associations between habitual school-day breakfast consumption, body mass index, physical activity and cardiorespiratory fitness in English schoolchildren. Eur J Clin Nutr, 64(10): 1086-1092.

Saudi Ministry of Education, 2017. Explanatory note and operational rules of the student's assessment list $1438 \mathrm{AH}$. https://departments.moe.gov.sa/GACEducationalPrograms/Forms/Pa ges/Rules.as (Accessed on May 15, 2019).

Scholey A, Harper S, Kenney D, 2001. Cognitive demand and blood glucose. Physiol Behav, 73: 585-592.

Taha Z, 2017. The effect of breakfast on academic performance among high school students in Abu Dhabi. AJNE, 2(1): 40-49.

Vishnukumar S, Sujirtha N, Ramesh R, 2018. The effect of breakfast on academic performance and behavior in school children from Batticaloa district. J Nutrit, 110: 159-165.

Wesnes K, Pincock C, Richardson D, Helm G, Hails S, 2003. Breakfast reduces declines in attention and memory over the morning in schoolchildren. Appetite, 41(3): 329-331.
Citation: Al Turki M, Al Shloi S, Al Harbi A, Al Agil A, Othman F, 2019. Effect of breakfast consumption on the cognitive and academic performances in schoolchildren: A cross sectional study in Riyadh, Saudi Arabia. Int Res J Med Med Sci, 7(3): 75-83. 